\title{
Effectiveness of an educational intervention on personal hygiene among school children in slum area of Kolkata, India
}

\author{
Anindya Mukherjee ${ }^{1}$, Abhik Sinha ${ }^{2}$, Pranita Taraphdar ${ }^{3}$ MD (Cal), Dibakar \\ Haldar ${ }^{4}$ MD (Cal), Sinha Debasish ${ }^{5}$ MD (Cal), Mohana Sinha ${ }^{6}$ DNB(Del) \\ ${ }^{1}$ Assistant Professor, Dept of Community Medicine, Medical College, Kolkata, India \\ ${ }^{2}$ Assistant Professor, Dept of Community Medicine, R.G Kar Medical College, Kolkata, India \\ ${ }^{3}$ Associate Professor, Dept of Community Medicine, NRS Medical College, Kolkata, India \\ ${ }^{4}$ Associate Professor, Dept of Community Medicine, R. G Kar Medical College, Kolkata, India \\ ${ }^{5}$ Assistant Professor, Dept of Community Medicine, North Bengal Medical College, Siliguri, West Bengal, India. \\ ${ }^{6}$ Senior Resident, Dept of Ophthalmology, Calcutta National Medical College, Kolkata ,India
}

\begin{abstract}
:
Background: Personal hygiene is the practice of maintaining cleanliness of the body. Primary school days are the best time to learn healthful habits and practice them, because as the child grows older, these habits become permanent. We intended to find out the existing level of knowledge, attitude and practice of personal hygiene and effectiveness of educational intervention among primary school children in a slum area of Kolkata. Methods: A quasi-experimental, controlled educational interventional study was conducted in two Bengali medium primary schools situated in area under service jurisdiction of Urban Health Centre-Chetla, Kolkata. During pre intervention phase, collection of socio-demographic information and assessment of knowledge, attitude and practice of personal hygiene of the students were done by pre designed pretested questionnaire and checklist. During the 6-month intervention in the study school lecture and demonstration on personal hygiene was done. Then post-testing in both the schools followed. Then personal hygiene education in the control school was imparted once and follow up of both the schools 3 months afterwards was done.

Results: There was significant improvement in the knowledge, attitude and practice level in study school as compared to the control school with educational intervention, but with a declining trend in study school during follow up visit. Parental literacy, occupation and per capita monthly family income were important sociodemographic attributes.
\end{abstract}

Conclusions: Sustained health education programme on personal hygiene with greater involvement of parents/ guardians may yield maximum benefit for the students.

Keywords: Educational intervention, Personal hygiene, school children, knowledge, attitude and practice, urban slum

\section{Introduction:}

Hygiene refers to practices associated with ensuring good health and cleanliness. Personal hygiene is the practice of maintaining cleanliness of ones own body. It is estimated that unsafe water, and lack of sanitation and hygiene every year claim lives of more than 1.5 million under five children from diarrhea ${ }^{1}$. In India, only $59 \%$ urban and $22 \%$ rural people have access to improved sanitation facilities ${ }^{2}$. The morbidities arising due to poor personal hygiene practices are more evident in the slum areas because of high population density, spread of respiratory infection, inadequate water supply, lack of sanitary facility, diarrhea and worm infestation, inadequate nutrition leading to anemia, malnutrition and vitamin deficiency ${ }^{3}$.

Children are future parents and what they learn is likely to be applied later in their lives. They can become change agents within their families and a stimulus to community development. Primary school days are the best time to learn healthful hygiene, because as the child grows older these habits become permanent and difficult to change ${ }^{4}$.

Against this background, the study was conducted to study the existing level of knowledge, attitude and practice of personal hygiene in primary school children in a slum and to assess the effectiveness of a health educational intervention programme.

\section{Methods:}

This school based educational interventional study was conducted from May 2008 - April 2009 in two primary schools situated in slum area of Chetla , the urban field practice area of All India Institute of Hygiene and Public Health, Kolkata. Two schools were selected randomly from the list of government primary schools in 
the field practice area. Alipur Abaitanik Vidyalaya was the experimental school and Adarsha Vidyalaya was the control school. Both schools were co-educational Vernacular (Bengali) medium primary schools (class I-IV) with study school having 74 students and control school having 269 students.

Children, whose parents consented for the study, were included in the study. The dropout rate was 9.5\% in study school and $10.8 \%$ in control school. The final study population was 67 children in the study school and 240 children in the control school $(\mathbf{n}=\mathbf{3 0 7})$.

The study tools used were a pre designed and pre tested schedule to record the socio-demographic and economic information of the students, a pre designed and pre tested closed ended questionnaire in vernacular to record the knowledge, attitude and practice of the students regarding personal hygiene, a pre designed and pretested course content with charts and posters to teach the personal hygiene to the students, prepared in the vernacular, a check list for recording of unhealthy practices, soap-water and toothpaste-brush for demonstration class. During the pre intervention phase (May08-June 08) the socio-demographic information of the students was obtained from their parents/guardians. Assessment of Knowledge, Attitude and Practice (KAP) of the study population on personal hygiene was also done. Next a checklist to corroborate the personal hygiene practice of the students in the school during thrice a week visit to each school with help of class monitors and teachers was completed.

During intervention phase (July08-Dec 08) in the study school, the following were done:

1. Lecture and demonstration on personal hygiene one class/month for each standard by researcher for 6 Months.

2. Training of teachers.

3. Weekly class in each standard for 6 months, by the school teachers

4. Similar questionnaire, checklist was used in October for KAP assessment.

In the control school only step 4 was done.

After completion of 6 months intervention phase, in January 2009, in both schools the knowledge, attitude and practice of the personal hygiene was done using the same questionnaire and checklist. At the end of the intervention, the students of the control school received education on personal hygiene as was done in the study school with one time lectures and demonstration by the researcher with similar explanation and handing over of contents to the teachers for teaching. Follow up of both the schools 3 months after in April 2009 for re testing of KAP was done.

A 15 item structured questionnaire was used to assess the level of knowledge. Grades allocated were Poor (0-5 questions correct, Max 33\% marks); Average (6-10 questions correct, Max 66\% marks) and Good (11-15 questions correct, Max 100\% marks).

To assess attitude, a 15 item structured questionnaire was used based on 5-point Likert's scale (very good, good, bad, very bad and do not know) for each statements and points awarded were 4,3,2,1 and 0 respectively, and classified as Poor (0-20 points), Average (21-40 points) and Good (41-60 points) according to total points.

To assess practices conducive to health under the sections on hair, ear, nose, throat, eyes, oro-dental, nails, foot, skin, sanitation and food habits ---2 marks were allotted for responses always/most of the time, 1 mark for occasional and 0 mark for rarely/never. The scores were graded as Poor - 0-20, Average 21-40, and Good 41-60.

Data was tabulated in MICROSOFT EXCEL 8.0 software and was analyzed with the help of EPI INFO3.4.3 software.

\section{Results:}

Socio-demographic information: most of the students in both the schools were males and Hindus. Numbers of students were much reduced in the higher classes in both schools, probably due to drop outs. Students mostly belonged to the nuclear families. Paternal and maternal literacy, occupation and per capita monthly family income were comparable in both the schools. (Table-1)

Baseline and final Knowledge, Attitude and Practice scores: There was no significant difference between the study and the control school regarding Knowledge, Attitude or Practice scores on personal hygiene obtained before intervention (adjusted for the standard of class). Most of the students got average scores in Knowledge, Attitude and Practice.

There was significant improvement in the knowledge, attitude and practice level in study school compared to control school with intervention. Mean knowledge, attitude and practice scores were significantly higher in the study school. (Table 2)

Mean knowledge, attitude and practice scores in both the schools as proportion of maximum obtainable scores showed upward trend in study school as compared to control school during the intervention phase. The students scored highest in knowledge domain but were weaker in attitude and weakest in the practice domain. 
During the follow up period there was a declining trend in the study school regarding marks obtained in all the domains but an increasing trend was noticed in control school after one time intervention. (Fig 1)

Association of knowledge, attitude and practice regarding personal hygiene with sociodemographic factors: Knowledge, attitude and practice scores were higher among higher age group students and the students of the higher classes. Parental literacy status, occupation and per capita monthly income of the families influenced the pre and post intervention knowledge score in both the schools. In the study school, attitude score was significantly higher among females, and in control school attitude score was significantly higher among students from nuclear families. The attitude score was significantly higher among students of parents with higher literacy status; students belonging to father/male guardian involved in desk work and among the richer students both before and after the study period. In the control school, the attitude score was significantly higher among the students belonging to the working mothers. Age group, class of study, literacy status of the parents, paternal occupation and per capita monthly family income was significantly associated with the practice score of the students in both the schools both before and after the study period. Family type and maternal occupation was significantly associated with practice score in the control school.

\section{Discussion:}

Knowledge regarding personal hygiene: An extensive nationwide school health education study in United States $^{5}$ found similar major deficiencies in the health knowledge of the elementary, secondary and above students, which corroborated well with our study. A study in rural schools of India ${ }^{6}$ showed similar post educational knowledge mean score increment as compared to pre educational level. That primary school students generally had poor to average knowledge of health aspects at the baseline was seen in a study from India ${ }^{7}$. The students scored average in health knowledge but were weaker in attitude and weakest in practice corroborating well with study on several school districts of Los Angeles ${ }^{8}$. In present study knowledge, attitude and practice scores were higher among higher age group students and the students of the higher classes, similar to findings in a study in an elementary school ${ }^{9}$. A declining trend of all the scores was seen in the study school during follow up visit corroborating with a study conducted in Hyderabad ${ }^{10}$. The students in the higher classes scored better both before and after study, which corroborated with the finding of a study in Australia ${ }^{11}$. Parental literacy influenced the pre and post intervention knowledge score in both schools, was similar to the findings of a study in Greece ${ }^{12}$. Paternal occupation of office work/teaching/shop keeping was associated with higher scores both before and after study. Similar findings were observed for students having working mothers, and families with higher per capita income. This observation though similar to other studies ${ }^{12}$ was dissimilar to the findings on rural school children in India ${ }^{6}$. In a study ${ }^{13}$ among the children aged 10-14 years in two secondary schools situated in Burdwan District of West Bengal knowledge, attitude and practice of students significantly improved after education.

Attitude regarding personal hygiene: The pre and post education assessment of the students regarding attitude towards personal hygiene showed similar trend like mean knowledge score both in the study school and the control school. There was significant dip in the attitude score in the study school students during the follow up period as compared to the end of the 6 month intervention period and inclined trend in the control school (though not significant). Similar changes in positive attitude were also observed in some studies ${ }^{6,11,15}$. The attitude score showed increasing trend with increase in age and class which corroborated well with some studies ${ }^{11}$ but differed with others ${ }^{6}$. That parental literacy and socio economic status influenced the attitude score of students was also found in other studies ${ }^{6},{ }^{14}$.

Practice regarding personal hygiene: Age group, class, parental literacy, paternal occupation and per capita monthly family income were significantly associated with the practice score of the students in both schools both before and after study corroborating the findings of other researchers ${ }^{7,11}$, and 13

Knowledge, attitude and practice of personal hygiene increased significantly among study school students after health education programme was undertaken but decreased after follow up period of no-intervention. Parental literacy, occupation and per capita monthly family income were important socio-demographic attributes. This study recommends sustained health education programmes on personal hygiene by both lecture and demonstration classes at regular intervals with greater involvement of parents/ guardians for maximum benefit of the students.

\section{Acknowledgements:}

Prof G K Pandey, Director, All India Institute of hygiene and Public Health, Kolkata Prof A Dasgupta, dept of PSM, All India Institute of hygiene and Public Health, Kolkata

Corresponding Author

Dr Abhik Sinha , ,Assistant Professor, Dept of Community Medicine ,R.G Kar Medical College ,Kolkata

281 Dumdum Park, Flat Number C/1, Kolkata 700055 Email : drabhiksinha08@ gmail.com 


\section{References:}

[1]. Towards better programming: A Manual on School Sanitation and Hygiene: UNICEF/IRC, Water, Environment and Sanitation Technical Guidelines Series. 1998; No. 5, p 1-2.

[2]. UNICEF: Progress for Children: A report card on water and sanitation, September 2006; (5).

[3]. Raghava Prasad K., School Health, Ind. Jour. of Com. Med.2005: 30 (4).

[4]. Kundu, N., "Understanding of Slums" ---case studies for the global reports on human settlements 2003. (Source: http: //www. ucl. ac. uk.) urban slum reports, the case of Kolkata, India.(cited on 13.02.2009)

[5]. Hilleboe H.E., Larimore G.W. and Sliepcevich E.M. Status of School Health Education in U.S.A., Intern. Jour. HIth. Educ. 1965; 8(2):72-77.

[6]. Dwivedi K.N., Tiwari I.C. and Marwah S.M. India: Innovations in Health Education in Rural Schools; Intern. Jour. Hlth. Educ. 1973;16(2):100

[7]. Gill P.S. and Prasad B.G. A Study Pinpoints Health Education Gaps Among Primary School Children; Intern. Jour. Hlth. Educ.1967;10(3): :179-183

[8]. Johns E.B. The School Health evaluation Study, Los Angeles Area: An Example of a Modern Evaluation Plant, Jour. Sch. Hlth.1962;32(1):5-11

[9]. Samman, A. (1962): Quoted by Young, M.A.C. Review of Research and Studies Related to Health Education Practice: School Health Education, Hlth. Educ. Monogr.1969; 28:88.

[10]. Champakam S., Santhamadhavan S. and Balasurbamanian, S.C. An assessment of the teaching of Nutrition in Elementary Schools in Hyderabad, Jour. Nutrit. Dietet. 1967; 4:41-50.

[11]. Homel P.J., Daniels P., Reid T.R. and Lawson J.S. Results of an Experimental School based Development Programme in Australia, Intern. Jour. Hlth. Educ.1981; 24(4):263-270.

[12]. Velonakis E., Karaitianon A., Yfantopoulos J., and Trichopoulos, D. Socio-economic Factors and school health Education in Greece, Hygie. 1984; 3(4):20-24.

[13]. Biswas AB, Roy AK, Das KK, Sen AK, Biswas R. A study of the impact of health education inparted to school children on their knowledge, attitude and practice in regard to personal hygiene; Ind J Pub Hlth. 1990; 34(2):87-92.

[14]. Biswas A.B. (1986): A Study of the Impact of the Health Education............ on Health Practices. M.D. thesis, p.40-51, 134-148.

[15]. Walvekar P.R., Naik V. A., Wantamutte A. S. and Mallapur M.D.: Impact of Child to Child Programme on Knowledge, Attitude Practice Regarding Diarrhoea among Rural School Children; Ind Jour.of Com. Med; 2006:31(2).

Table 1: Comparison of the students of the study school and control school according to the sociodemographic attributes $(n=307)$

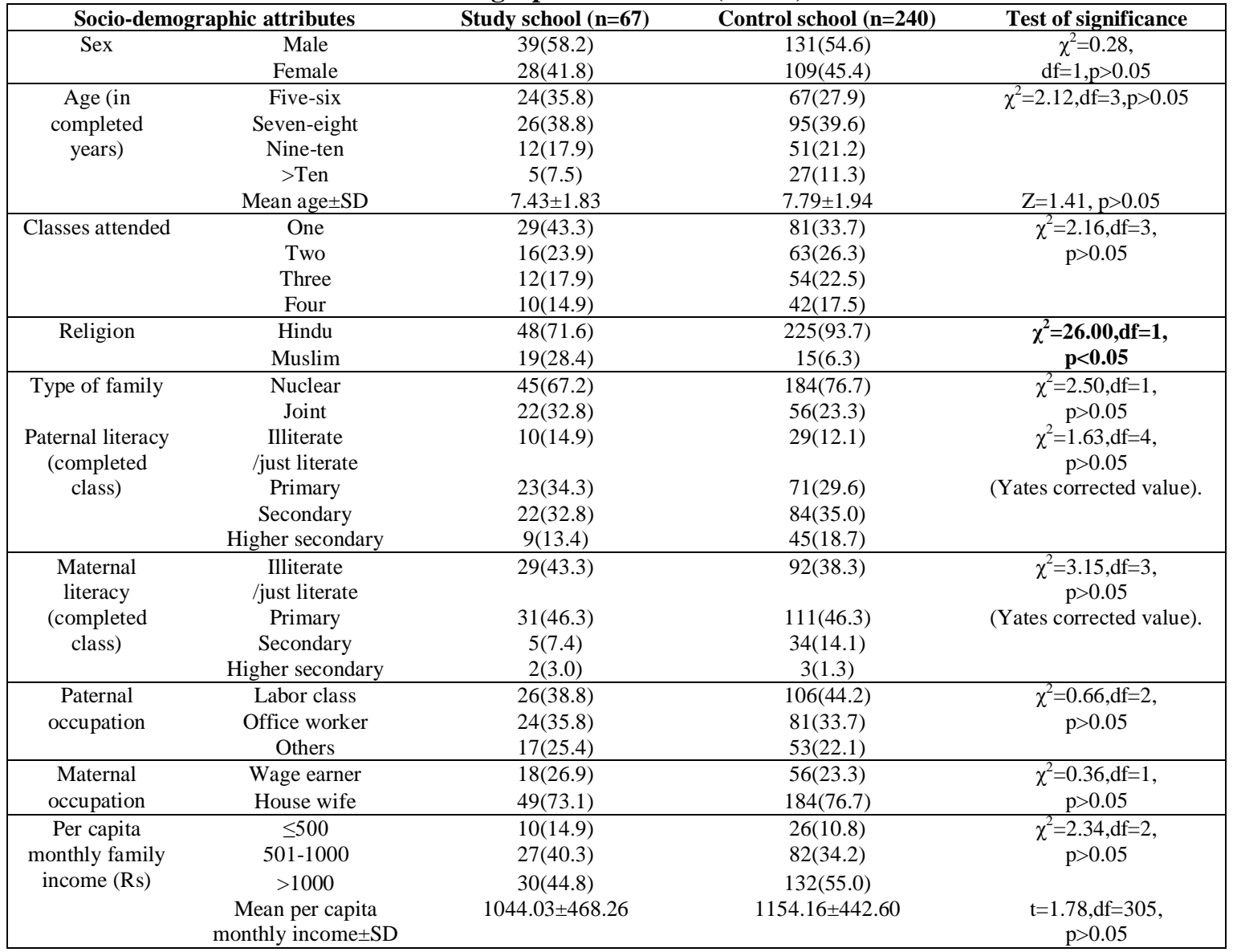




\begin{tabular}{|c|c|c|c|c|c|c|c|c|}
\hline \multirow{2}{*}{$\begin{array}{c}\text { Category } \\
\text { Of students } \\
\text { And mean score }\end{array}$} & \multicolumn{4}{|c|}{ Study school $(n=67)$} & \multicolumn{4}{|c|}{ Control school $(n=240)$} \\
\hline & $\begin{array}{l}\text { Before } \\
\text { study }\end{array}$ & $\begin{array}{c}\text { After } 3 \mathrm{M} \text { of } \\
\text { study }\end{array}$ & $\begin{array}{c}\text { After } 6 \mathrm{M} \\
\text { of study }\end{array}$ & $\begin{array}{l}\text { Follow } \\
\text { up } 3 \mathrm{M}\end{array}$ & $\begin{array}{l}\text { Before } \\
\text { study }\end{array}$ & $\begin{array}{c}\text { After } 3 \mathrm{M} \text { of } \\
\text { study }\end{array}$ & $\begin{array}{c}\text { After } 6 \mathrm{M} \\
\text { of study }\end{array}$ & $\begin{array}{l}\text { Follow } \\
\text { up } 3 \mathrm{M}\end{array}$ \\
\hline \multicolumn{9}{|c|}{ Knowledge score obtained } \\
\hline $\begin{array}{l}\text { Poor } \\
(0-5)\end{array}$ & $\begin{array}{c}11 \\
(16.4)\end{array}$ & 0 & 0 & 0 & $\begin{array}{c}27 \\
(11.3)\end{array}$ & $\begin{array}{c}18 \\
(7.5)\end{array}$ & $\begin{array}{c}11 \\
(4.6)\end{array}$ & 0 \\
\hline Average & 44 & 36 & 20 & 24 & 174 & 174 & 180 & 158 \\
\hline$(6-10)$ & $(65.7)$ & $(53.7)$ & $(29.9)$ & $(35.8)$ & $(72.5)$ & $(72.5)$ & $(75.0)$ & $(65.8)$ \\
\hline Good & 12 & 31 & 47 & 43 & 39 & 48 & 49 & 82 \\
\hline$(11-15)$ & $(17.9)$ & $(46.3)$ & $(70.1)$ & $(64.2)$ & $(16.2)$ & $(20.0)$ & $(20.4)$ & $(34.2)$ \\
\hline Mean score & $8.39 \pm$ & $10.18 \pm$ & $12.19 \pm$ & $11.01 \pm$ & $8.23 \pm$ & $8.40 \pm$ & $8.68 \pm$ & $9.53 \pm$ \\
\hline & 2.28 & 2.13 & 1.95 & 1.73 & 2.12 & 1.97 & 1.90 & 1.63 \\
\hline
\end{tabular}

Table2: comparison of the students of the 2 schools according to knowledge, attitude and practice score obtained before, after 3 months, after 6 months of the study with follow up after 3 months.

\begin{tabular}{|c|c|c|c|c|c|c|c|c|}
\hline \multicolumn{9}{|c|}{ Attitude score obtained } \\
\hline Poor & 14 & 5 & 0 & 2 & 40 & 35 & 30 & 24 \\
\hline$(0-20)$ & (20.9) & (7.5) & & (3.0) & $(16.7)$ & $(14.6)$ & (12.5) & $(10.0)$ \\
\hline Average & 49 & 53 & 41 & 52 & 186 & 188 & 193 & 197 \\
\hline$(21-40)$ & $(73.1)$ & $(79.1)$ & (61.2) & $(77.6)$ & $(77.5)$ & $(78.3)$ & $(80.4)$ & $(82.1)$ \\
\hline Good & 4 & 9 & 26 & 13 & 14 & 17 & 17 & 19 \\
\hline$(41-60)$ & $(6.0)$ & (13.4) & $(38.8)$ & (19.4) & $(5.8)$ & $(7.1)$ & $(7.1)$ & $(7.9)$ \\
\hline Mean score & $28.25 \pm$ & $33.48 \pm$ & $39.07 \pm$ & $35.36 \pm$ & $27.18 \pm$ & $27.60 \pm$ & $28.11 \pm$ & $28.24 \pm$ \\
\hline & 7.35 & 7.47 & 7.70 & 7.10 & 6.93 & 6.64 & 6.85 & 6.80 \\
\hline \multicolumn{9}{|c|}{ Practice score obtained } \\
\hline Poor & 26 & 21 & 17 & 22 & 105 & 79 & 86 & 34 \\
\hline$(0-20)$ & $(38.8)$ & $(31.3)$ & $(25.4)$ & $(32.8)$ & $(43.8)$ & (32.9) & $(35.8)$ & $(14.2)$ \\
\hline Average & 40 & 43 & 38 & 42 & 133 & 158 & 150 & 200 \\
\hline$(21-40)$ & $(59.7)$ & $(64.2)$ & $(56.7)$ & $(62.7)$ & $(55.4)$ & $(65.8)$ & $(62.5)$ & $(83.3)$ \\
\hline Good & 1 & 3 & 12 & 3 & 2 & 3 & 4 & 6 \\
\hline$(41-60)$ & $(1.5)$ & $(4.5)$ & $(17.9)$ & $(4.5)$ & $(0.8)$ & $(1.3)$ & $(1.7)$ & $(2.5)$ \\
\hline \multirow[t]{2}{*}{ Mean score } & $21.79 \pm$ & $25.73 \pm$ & $31.13 \pm$ & $27.34 \pm$ & $21.57 \pm$ & $22.85 \pm$ & $23.52 \pm$ & $25.51 \pm$ \\
\hline & 9.84 & 9.06 & 9.61 & 9.04 & 7.89 & 6.85 & 6.39 & 6.09 \\
\hline
\end{tabular}

Figures in parenthesis indicate percentages. $M=$ months

Figure1: distribution of students of both schools according to average scores obtained as \% of maximum possible scores in Knowledge, attitude and practice.

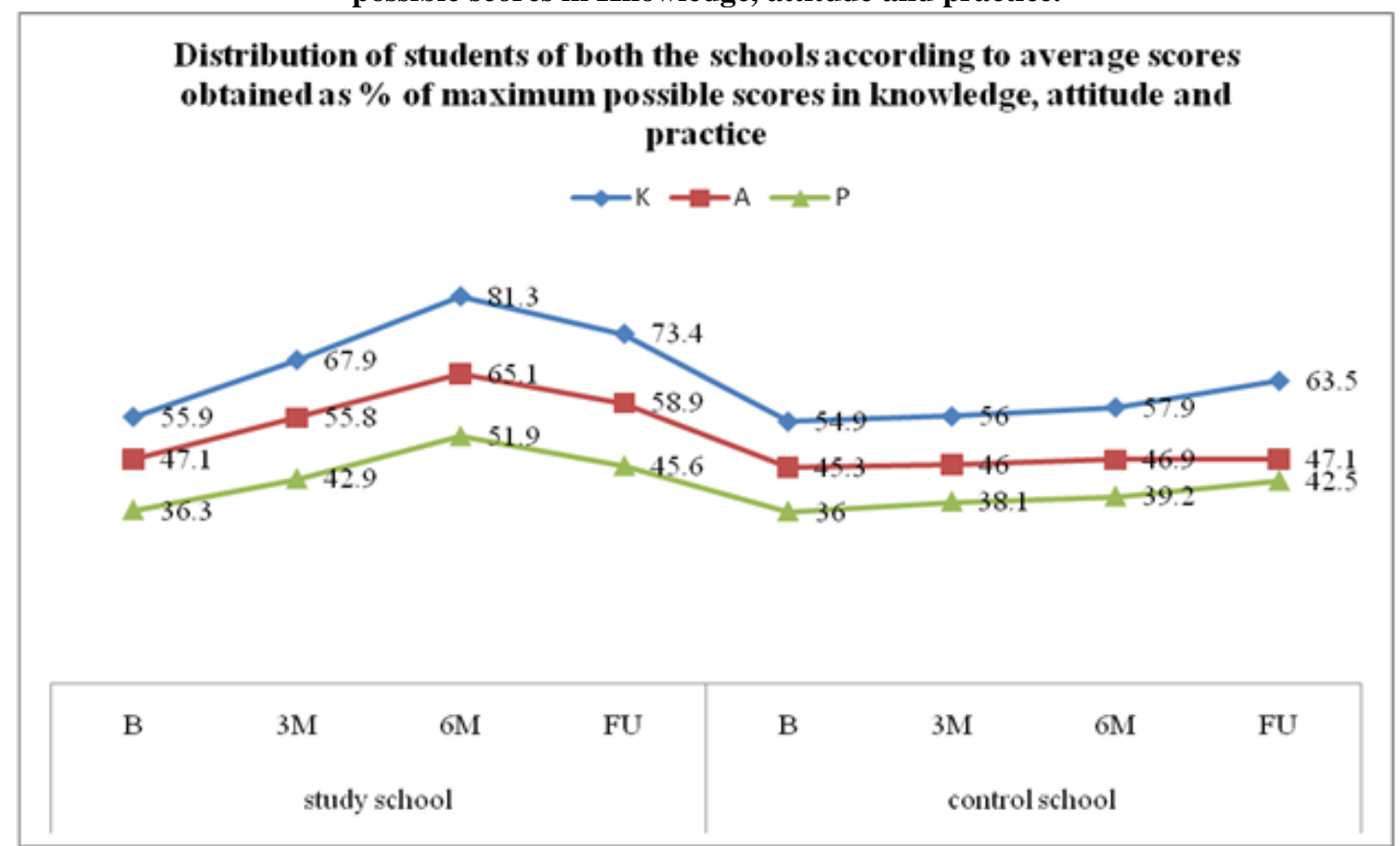

$\mathrm{B}=$ baseline, $3 \mathrm{M}=$ at 3 month of intervention point, $6 \mathrm{M}=$ at 6 month (end) of intervention point, $\mathrm{FU}=3$ month follow up point. 